\title{
SELECTION OF ALTERNATIVE FARM WORK PLAN BY INTEGRATED AHP/DEA TECHNIQUE
}

\author{
Yinsheng Yang and Masayuki Koike \\ Institute of Agricultural and Forest Engineering, University of Tsukuba \\ 1-1-1 Tennodai, Tsukuba, Ibaraki 305-8572, Japan \\ yangys@sakura.cc.tsukuba.ac.jp
}

\begin{abstract}
This study addresses the integrated AHP/DEA technique for selection of alternative farm work plan by combining analytic hierarchy process (AHP) and data envelopment analysis . (DEA), which takes DEA as a central model and AHP as auxiliary model. AHP model can not only quantify some subjective criteria to provide the needed data for DEA model but also predetermine the weight regions to provide some important preference information related to criteria for AR/DEA so as to make the evaluation more fair both subjectively and objectively. Choosing six criteria and thirteen alternative plans, this study also presents an application of integrated AHP/DEA technique in selection of farm work plan for a specific region of Indonesia. The applicability of integrated AHP/DEA shows that this technique can be added to the model and algorithm databases of the developed DSS for the optimization of group farm work planning.
\end{abstract}

\section{Introduction}

It is a well-known fact that agriculture is a multisystemed and multihierarchial complex system which involves many kinds of problems. To solve those problems effectively by means of systems science method is a very important topic for a high yield, high efficiency, high quality and sustainable agriculture even for precision farming (PF). In order to stabilize agricultural productions, it is also necessary to design the appropriate farm work plan simultaneously considering the natural environment, socio-economic conditions and the level of the technology from one region to another. Pertiwi et al. (1991) developed a decision support system (DSS) for the optimization of group farm work planning and proposed its applicability to a developing country like Indonesia. Also, they (1992) introduced two multicriterion decision methods including analytic hierarchy process (AHP) (Saaty, 1980) and compromise programming (CP) (Yu, 1985) 
into the developed DSS for the selection of alternative farm work plan with six criteria. Although AHP and $\mathrm{CP}$ were available, we found that there are some shortcomings to them. First, although AHP is an effective approach for multicriterion decision making, especially involving subjective judgment on feelings, ideas and emotions, it is a fixed weights and uniform method without attaining optimality because it uses pairwise comparisons and eigenvector to determine the prior weights of all criteria and alternatives, and the values are common to all alternative objects. Second, the obtained result from $\mathrm{CP}$ has a great deal to do with the selection of the scalar and different scalar maybe lead different prior relations. In order to overcome the shortcomings of AHP as above, we will introduce data envelopment analysis (DEA) (Charnes et al., 1994) into selection of alternative farm work plan in combination with AHP in the current study. DEA determines the weights and priority by solving the mathematical programining corresponding to each alternative which is called decision making unit (DMU) in DEA. Hence, the weights differ from one DMU to another and DEA is a variable weights and non-uniform method. Because the weights are determined in such a way that they should be most favorable to the DMU concerned, the obtained priority relations among alternatives are relatively optimal.

As to the comparative and combined study on AHP and DEA, we found but a few research works. Tone (1989) pointed out structural similarities between AHP and DEA in case of the benefit/cost analysis and suggested their potential trades. Shang and Sueyoshi (1995) presented a unified framework for the selection of a flexible manufacturing system (FMS) by incorporating AHP and DEA. Seifert and Zhu (1998) combined assurance region data envelopment analysis (AR/DEA) with AHP to put forward a weighted DEA approach and its application in identifying excesses and deficits in Chinese industrial productivity (1953-1990). The objective of this study is to introduce the integrated AHP/DEA technique to selection of alternative farm work plan by incorporating the potential trades of AHP and DEA, which takes DEA as a central model and AHP as auxiliary model. AHP model can not only quantify some subjective criteria to provide the needed data for DEA model but also predetermine the weight regions to provide some important preference information related to criteria for AR/DEA so as to make the evaluation more fair subjectively and objectively.

\section{Integrated AHP/DEA technique}

Based on the spirits of the previous research efforts and the objective of the current study, we summarize the integrated AHP/DEA technique as shown in Fig.1. 


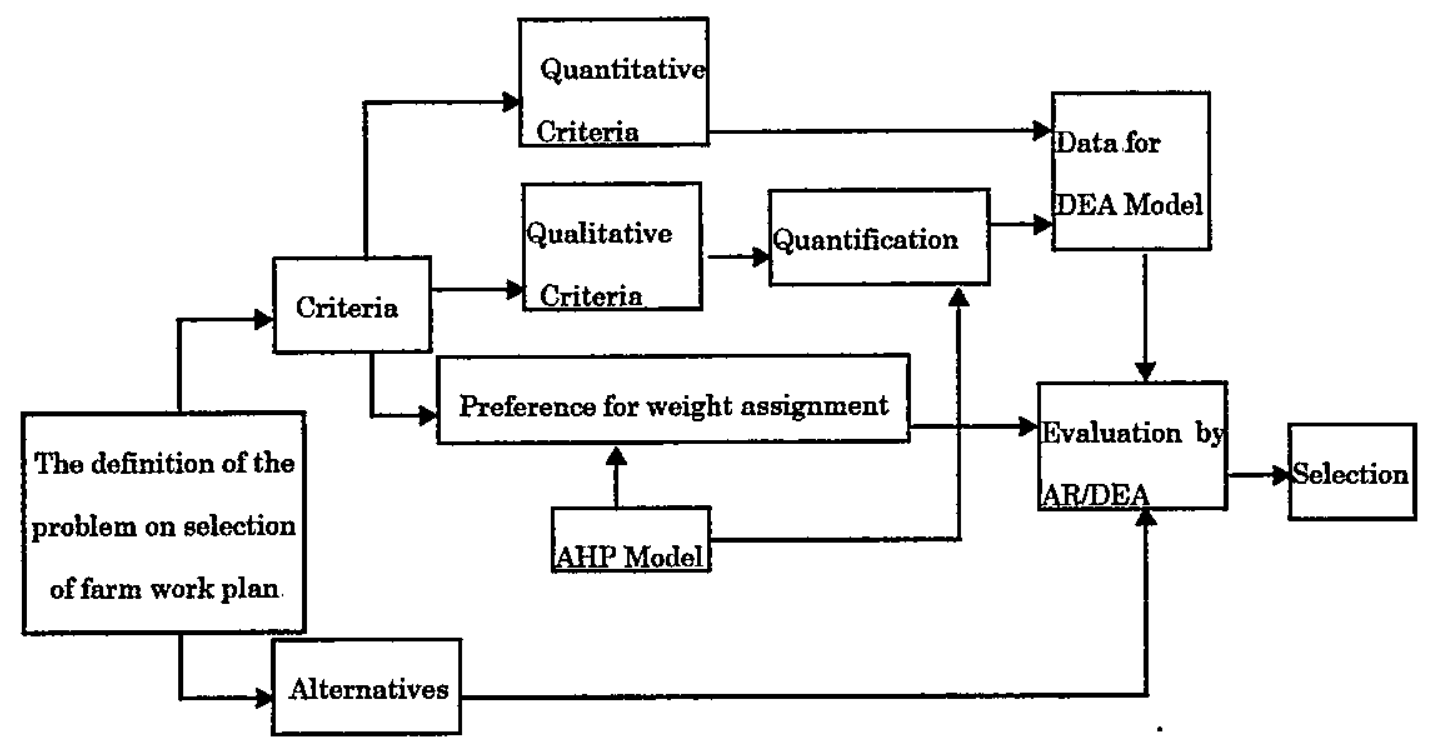

Fig. 1 The structure and function of integrated AHP/DEA technique

\section{Selection of alternative farm work plan}

This study uses the same criteria selected by Pertiwi et al.(1992) to evaluate comprehensively thirteen alternatives for farm work of a specific region in Indonesia.

\section{Selected criteria}

Six criteria were selected, denoted as A-F, respectively. A: initial cost of machinery (thousand Yen, Yen is Japanese monetary); B: operation cost (Yen); C: working duration of labors (day); D: farm work plan stability (\%); E: technological consideration; F: managerial consideration. Obviously, initial cost of machinery and operation cost are negative criteria (the smaller the value, the better), and farm work plan stability, technological consideration and managerial consideration are positive criteria ( the greater the value, the better). It is noteworthy that working hours of labors is also positive criterion with consideration of the realistic situation for maintaining agricultural labors in Indonesia.

\section{Quantification of qualitative criteria and predetermination of weight regions}

Since both technological and managerial considerations are qualitative criteria with great subjectivity, AHP model was provided to quantify them. Columns 6 and 7 of Table 1 show the quantified values by pairwise and eigenvectors. The first column lists the codes of thirteen plans and other columns list the values of other 
criteria

Table 1 The values of six criteria for thirteen alternative farm work plans

\begin{tabular}{ccccccc}
\hline & \multicolumn{7}{c}{ Criterion } \\
\cline { 2 - 7 } Code of plan & $\mathrm{A}$ & $\mathrm{B}$ & $\mathrm{C}$ & $\mathrm{D}$ & $\mathrm{E}$ & $\mathrm{F}$ \\
\hline AR1-1 & 3200 & 22750 & 16.5 & 100 & 0.100 & 0.021 \\
AR1-2 & 2560 & 21200 & 16.5 & 100 & 0.100 & 0.031 \\
AR1-3 & 1920 & 19700 & 16.5 & 100 & 0.100 & 0.044 \\
AR2-1 & 1550 & 16800 & 16.5 & 100 & 0.025 & 0.129 \\
AR2-2 & 1400 & 16400 & 16.5 & 100 & 0.025 & 0.129 \\
BR1-1 & 3200 & 26800 & 33.4 & 98 & 0.100 & 0.021 \\
BR1-2 & 2560 & 25300 & 33.5 & 90 & 0.100 & 0.036 \\
BR1-3 & 1920 & 20300 & 18.9 & 72 & 0.100 & 0.048 \\
BR1-4 & 1280 & 22400 & 33.8 & 72 & 0.100 & 0.078 \\
BR2-1 & 1550 & 17500 & 18.9 & 90 & 0.025 & 0.129 \\
BR2-2 & 1400 & 17150 & 18.9 & 90 & 0.025 & 0.129 \\
BR2-3 & 1200 & 22250 & 33.8 & 67 & 0.100 & 0.078 \\
BR2-4 & 720 & 17630 & 23.8 & 67 & 0.100 & 0.129 \\
\hline
\end{tabular}

To reflect the preference of decision makers to different criteria, three types of weight assignments were predetermined by AHP(Pertiwi et al., 1992) with three types of emphasis on economy, sociality and stability, respectively. On the basis of those weight assignments, we can derive the following weight region represented by inequalities:

$$
\begin{aligned}
& 1.74 \leq \omega_{2} / \omega_{1} \leq 2.77 \\
& 0.36 \leq \mu_{2} / \mu_{1} \leq 1.61 \\
& 0.157 \leq \mu_{3} / \mu_{2} \leq 0.565 \\
& \mu_{4} / \mu_{3}=1
\end{aligned}
$$

\section{AR/DEA Model}

Replacing inputs and outputs with negative and positive criteria respectively, the DEA model for selection of alternative farm work plans with thirteen DMUs can be described as follows.

$$
\begin{array}{ll}
M a x & h_{j_{0}}=\sum_{r=1}^{4} \mu_{r} y_{r j_{0}} \\
\text { s.t. } & \sum_{i=1}^{2} \omega_{i} x_{i j}-\sum_{r=1}^{4} \mu_{r} y_{r j} \geq 0, j=1, \ldots, 13
\end{array}
$$




$$
\begin{aligned}
& \sum_{i=1}^{2} \omega_{i} x_{i j}=1 \\
& \omega_{i} \geq 0, \mu_{r} \geq 0(i=1,2 ; r=1,2,3,4)
\end{aligned}
$$

Here, $x_{i j}$ denote the value of input $i(i=1,2)$ to $\mathrm{DMU}_{\mathrm{j}}(\mathrm{j}=1, \ldots, 13)$ and $y_{r j}$ denote its value of output $r(r=1,2,3,4)$. We can obtain the prior values of all the DMUs through solving this linear programming thirteen times by setting each DMU as target $D M U j_{0}$ in turn. Suppose that the optimum solution is $h_{j_{0}}^{*}, \omega_{i}^{*}(i=1,2), \mu_{r}^{*}(r=1,2,3,4)$, then $h_{j_{0}}^{*}$ reflects the priority of the $j_{0}$ th alternative plan and the greater it is ,the greater its priority is. $\omega_{i}^{*}(i=1,2), \mu_{r}^{*}(r=1,2,3,4)$ is most favorable to the $j_{0}$ th alternative plan. While considering the preference and adding the weight region to the programming above as additional constraints, DEA model becomes AR/DEA model.

\section{Results}

Table 2 presents the results obtained by AR/DEA model. The $2^{\text {nd }}$ and $3^{\text {rd }}$ columns show prior values and prior orders of thirteen plans, respectively. The succeeding columns show the most favorable weight assignments of all plans to all criteria. Obviously, the optimal farm work plan is BR2-4.

Table 2 The result evaluated by AR/DEA

\begin{tabular}{ccccccccc}
\hline $\begin{array}{c}\text { Code of } \\
\text { plan }\end{array}$ & $\begin{array}{c}\text { Prior } \\
\text { value }\end{array}$ & $\begin{array}{c}\text { Prior } \\
\text { order }\end{array}$ & A & B & C & D & E & F \\
\hline AR1-1 & 0.414 & 13 & 0.00261 & 0.00723 & 0.00230 & 0.00370 & 0.00058 & 0.00058 \\
AR1-2 & 0.505 & 9 & 0.00318 & 0.00880 & 0.00279 & 0.00450 & 0.00071 & 0.00071 \\
AR1-3 & 0.646 & 8 & 0.00406 & 0.0112 & 0.00357 & 0.00574 & 0.00090 & 0.00090 \\
AR2-1 & 0.791 & 4 & 0.00496 & 0.0137 & 0.00436 & 0.00702 & 0.00110 & 0.00110 \\
AR2-2 & 0.860 & 2 & 0.00539 & 0.0149 & 0.00474 & 0.00763 & 0.00120 & 0.00120 \\
BR1-1 & 0.433 & 12 & 0.00254 & 0.00703 & 0.00223 & 0.00359 & 0.000564 & 0.000564 \\
BR1-2 & 0.502 & 10 & 0.00307 & 0.00849 & 0.00753 & 0.00271 & 0.000426 & 0.000426 \\
BR1-3 & 0.491 & 11 & 0.00403 & 0.0112 & 0.00354 & 0.00570 & 0.000895 & 0.000895 \\
BR1-4 & 0.785 & 6 & 0.00526 & 0.0146 & 0.0129 & 0.00465 & 0.00073 & 0.00073 \\
BR2-1 & 0.724 & 7 & 0.00491 & 0.0136 & 0.00432 & 0.00696 & 0.00109 & 0.00109 \\
BR2-2 & 0.786 & 5 & 0.00533 & 0.0148 & 0.00469 & 0.00755 & 0.00119 & 0.00119 \\
BR2-3 & 0.797 & 3 & 0.00551 & 0.0153 & 0.0135 & 0.00487 & 0.000764 & 0.000764 \\
BR2-4 & 1.000 & 1 & 0.00974 & 0.0169 & 0.0190 & 0.00685 & 0.00387 & 0.00387 \\
\hline
\end{tabular}




\section{Summary}

This study presents integrated AHP/DEA technique for selection of alternative farm work plan, which can integrate favorable aspects of both AHP and DEA to realize comprehensive evaluation with the unification of subjectivity and objectivity. The result evaluated in such a way is more reasonable due to its optimality. The applicability of integrated AHP/DEA shows that this technique can be added to the model and algorithm databases of the developed DSS for the optimization of group farm work planning.

\section{References}

Pertiwi, S., Konaka, T. and Koike, M. (1991), “Decision Support System for the Optimization of Group Farm Work Planning From Land Preparation to Transplanting on Paddy Field by Auto-simulation," Japanese Journal of Farm Work Research, 26(Special Issue 1), 23-24.

Pertiwi, S., Konaka, T. and Koike, M. (1992), “ Selection of Alternative Farm Work Plan by Multicriterion Decision-making Technique," Japanese Journal of Farm Work Research, 27, 36-46.

Saaty, T.L. (1980), The Analytic Hierarchy Process, McGraw-Hill.

Yu, P.L. (1985), Muitiple Criteria Decision Making, Plenum Press, New York.

Charnes, A., Cooper, W.W., Lewin, A.Y. and Seiford, L.S. (1994), Data Envelopment Analysis: Theory, Methodology and Application, Kluwer Academic Publishers.

Tone, K. (1989), " A Comparative Study on AHP and DEA," International Journal of Policy and Information, 13, 57-63.

Shang, J. and Sueyoshi, T. (1995), “ A Unified Framework for the Selection of a Flexible Manufacturing System," European Journal of Operational Research, 85, 297-315.

Seifert, L.M. and Zhu, J. (1998), "Identifying Excesses and Deficits in Chinese Industrial Productivity (1953-1990): a Weighted Data Envelopment Analysis Approach," OMEGA: International Journal of Management Science, 26, 279-296. 